\title{
Risk factors for Covid-19 in India
}

\author{
Manas Pratim Roy \\ Public Health Specialist, Ministry of Health and Family Welfare, New Delhi, India
}

\begin{abstract}
Like many developing countries, India was devastated by the raging pandemic of Covid-19. With the active involvement of the government and the community, the disaster was fought with. However, the impact was uneven across the country. The present study aimed to identify the factors responsible for variation in case burden of Covid-19. Data on demographic factors and co-morbidities were obtained from different sources available in the public domain. Descriptive statistics were used for comparison between states. A total of 30 states were taken into account. Correlation was used to find out association between different factors and the burden of Covid-19. Data on Covid were collected till $9^{\text {th }}$ May, 2021. The burden of Covid-19 was strongly related to the literacy status and economy of the state $(r=0.574$ and 0.730 , respectively). The burden of self-reported hypertension and diabetes was also statistically linked to the burden of Covid-19 ( $\mathrm{r}=0.539$ and 0.721 , respectively). Overweight and obesity were also associated with the burden of Covid-19 ( $\mathrm{r}=0.614$ and 0.561 , respectively). Therefore, in areas with a high proportion of patients with co-morbidities, limited resources may be mobilized for a better outcome. As the states with poor literacy and health condition suffered the most, tailored intervention is wanted to reach the poor and vulnerable.
\end{abstract}

Correspondence: Dr. Manas Pratim Roy, Ministry of Health and Family Welfare, New Delhi, India.

Tel. +91-9871073375

E-mail: manas_proy@yahoo.co.in

Key words: Covid-19; co-morbidity; literacy.

Conflict of interest: The author declares no competing interests. Contributions: MPR reviewed the literature, analyzed data and wrote the manuscript.

Ethics approval: Institutional Review Board approval was not required as no individual data was handled and all data utilized are in public domain.

Received for publication: 29 May 2021.

Accepted for publication: 9 August 2021.

${ }^{\circ}$ Copyright: the Author(s), 2021

Licensee PAGEPress, Italy

Monaldi Archives for Chest Disease 2022; 92:1954

doi: 10.4081/monaldi.2021.1954

This article is distributed under the terms of the Creative Commons Attribution Noncommercial License (by-nc 4.0) which permits any noncommercial use, distribution, and reproduction in any medium, provided the original author(s) and source are credited.

\section{Introduction}

Like many developing countries, India was devastated by the raging pandemic of Covid 19. Till $9^{\text {th }}$ May 2021, India has recorded 22.3 million cases [1]. Even after ongoing vaccination efforts, the cases are rising with the passage of every single day. Non-pharmacological interventions like social distancing, use of masks, personal cleanliness and restriction in people's movement were attempted with variable success across the country. While many medical factors were considered for the spread of the pandemic, socio-demographic factors like age, economic condition and presence of comorbidities stood crucial at the individual level, rendering some people more vulnerable than others to contact and at times, to succumb to the novel virus [2]. Recent meta-analyses suggested the presence of co-morbidities in Covid patients [3,4]. Identification of such factors is important in public health for mobilizing limited resources to the most vulnerable patients. Without specific drugs for the novel virus, prevention remains the most important strategy for mitigation of the pandemic.

However, as we are gradually expanding our knowledge base about the virus, it has been felt that there is a lack of sufficient literature at the national level from India on the role of underlying diseases in contacting Covid-19. Therefore, an effort was made to understand the relationship between the prevalence of the risk factors and the extent of case burden of Covid-19 in different states in India.

\section{Methods}

All 30 states were considered for analysis. The proportion of people above 60 years of age was taken. The presence of risk factors like diabetes, hypertension and chronic lung disease were considered for people above 45 years of age (self-reported). Chronic lung diseases include chronic obstructive pulmonary disease (COPD), asthma and chronic bronchitis (any one or more). Physically active (self-reported) was defined as those who are either engaged in moderate physical activity (at least $75 \mathrm{~min}$ throughout the week) or vigorous physical activity (at least 150 min throughout the week) or an equivalent combination of moderate- and vigorous-intensity activity. Overweight and obesity were decided based on body mass index levels (overweight 25.0 to 29.9 and obese $\geq 30.0$ ). The participants were asked about the presence of different co-morbidities during the survey and their responses were not verified clinically. All these factors were taken from the reports on Longitudinal Ageing Study in India (LASI), wave I [5]. It is the largest longitudinal study on ageing in the world. Conducted among the age group of 45 years and older in 2017-18, this study covered 30 states on health, social and economic aspects. Self-reporting data on co-morbidities were considered. Per capita net state domestic product, an indicator for the finan- 
cial condition, was considered for the states for 2018-19 [6]. The data were taken from the annual financial report published by the Government. Covid tests done per million and confirmed Covid cases per million were considered and data were taken till $9^{\text {th }}$ May, 2021 [1]. Such data were available in Covid19India, a website compiling data from the both central and state Government sources. In India, Covid-19 was diagnosed based on RT-PCR or rapid antigen test. Information on hospitalization and/or mortality rate was beyond the scope of this paper. The data on literacy (in people $>7$ years of age) was taken from National Sample Survey (2017-18) [7]. The survey covered more than 113,000 population from the entire country on different health related aspects.

The required data were entered in the spreadsheet using Microsoft Excel. The correlation coefficient was calculated between different risk factors and Covid-19case load and tests performed. Scatter plot was used to depict the relationship between the risk factors and burden of Covid-19. $\mathrm{P}<0.5$ was considered significant. PASW for Windows software (version 19.0; SPSS Inc., Chicago, USA) was used. The study did not require an Ethical Committee review as the data were in the public domain and no individual data were handled.

\section{Results}

The study found considerable variation in the demographic and health parameters of the states. Poor states like Bihar, Uttar Pradesh and Madhya Pradesh always remained lagging, when it comes to the number of people tested per million. Goa, Delhi and Kerala recorded maximum cases per million $(75,463,6,800$ and 53,148 , respectively)
(Figure 1). These three states conducted more tests for Covid-19 than most of the other states. Kerala and Goa have a high proportion of elderly people (39.1\% and $29.6 \%$, respectively). Goa recorded the highest concentration of hypertensive people (40.8\%). When it comes to diabetes, Goa and Kerala topped the list (21.9\% and 27.4\%, respectively). Rajasthan and Kerala have the highest concentration of patients suffering from CLD (10.3\% and 9\%, respectively).

It was noted that with literacy, the case burden $(\mathrm{r}=0.574$, $\mathrm{p}=0.005$ ) was correlated significantly but not the number of tests done $(r=0.410, p=0.058)$. Economy was also associated with case burden and the number of tests done $(r=0.730$ and 0.510 , respectively). When the relationship of Covid-19 burden was tested with self-reported hypertension and diabetes, both were found to be strongly positive. $(r=0.539, p=0.003$ and $r=0.721, p=0.000$, respectively). Overweight and obesity were also associated with the burden of Covid-19 ( $\mathrm{r}=0.614, \mathrm{p}=0.000$ and $0.561, \mathrm{p}=0.002$, respectively) (Figure 2). CLD, physically active people and the proportion of people $>60$ years of age were not significant.

\section{Discussion}

The present study is an effort to understand the risk factors for Covid-19 from the Indian perspective. By adopting an ecologic approach, the study focused on possible population level interventions. Along with certain co-morbidities, demographic factors like literacy and the proportion of elderly people have been considered here. Although age was not a risk factor for the present paper, literacy was associated with the Covid burden. It may determine the individual exposure to Covid-19, as there is less need for a higher

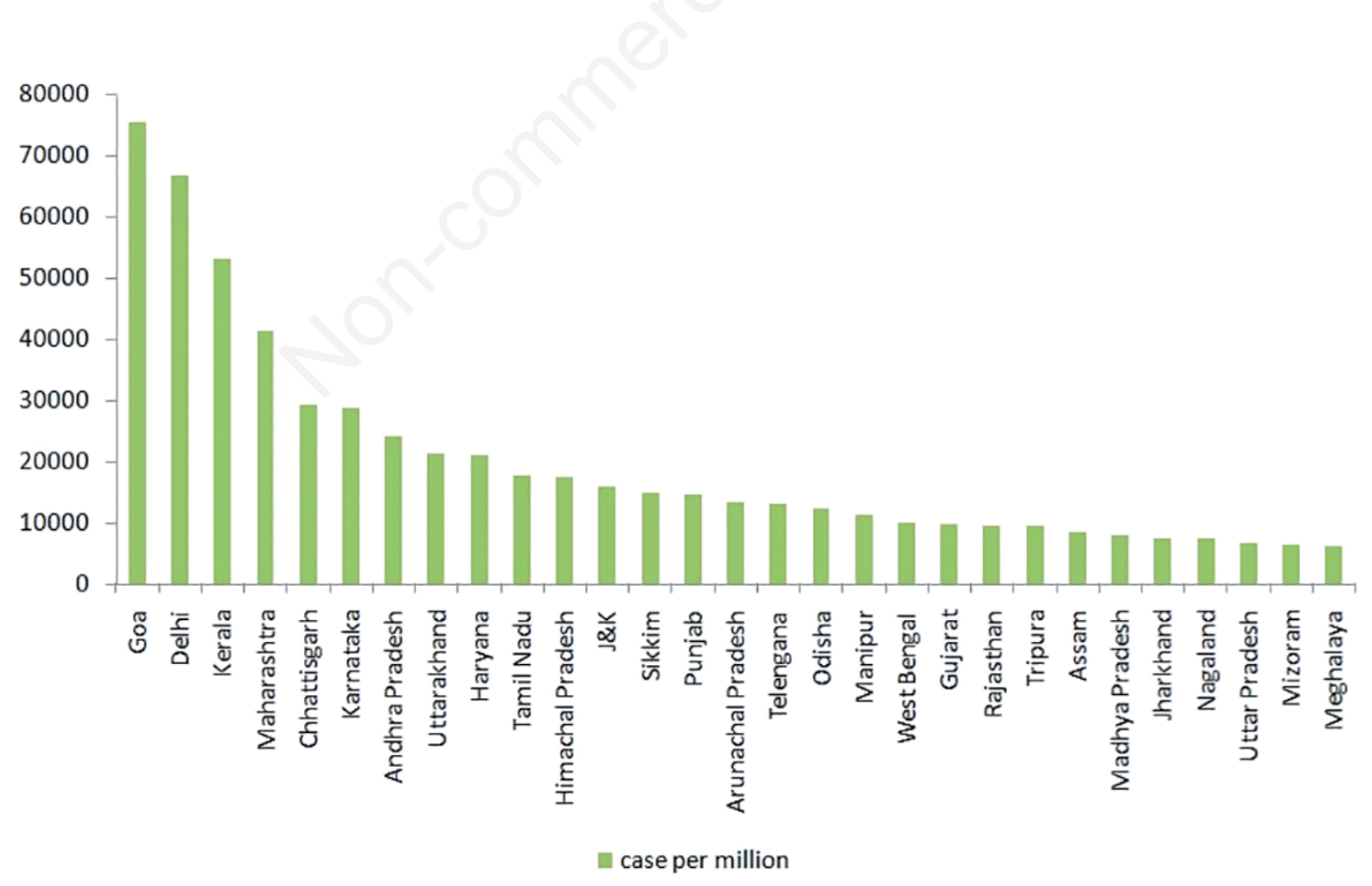

Figure 1. Covid cases per million in Indian states. 
educational qualification for frontline and manual workers [2]. Besides, literacy may impact the adherence to public health guidelines for prevention and the decision to go for testing. Illiterate people are more likely to have less knowledge on Covid-19, making them vulnerable to the pandemic [8]. In places with a higher literacy rate, people are willing to get themselves tested because of higher consciousness. The same attitude may decide people's willingness to a vaccine in the future.

Economy is another important factor. High mortality from areas with low socio-economic status (SES) has been reported earlier [9]. People in these areas are more often unemployed or engaged in informal work. In our set up, states with poor economic condition always lagged behind, in terms of testing rate for Covid and expanding surveillance activities. Better testing rate in affluent areas are a known finding during Covid pandemic [10].

Co-morbidities were seen earlier to put people at higher risk for developing Covid [3,4]. Covid-19 burden was strongly associated with tested the burden of diabetes, as found by the present paper. Kerala, Goa and Delhi - three states worst hit by diabetes also suffered the maximum impact of Covid-19. Diabetes mellitus is thought to be a risk factor associated with acute respiratory distress syndrome in patients with Covid-19 [11,12]. Dysregulated glycemia may lead to hypercoagulable state through the activation of plasmin, thrombin and monocytesmacrophages [13]. Diabetics suffer from a continuous low-grade inflammation which plays an important role in cytokine storm, an event implicated for the severity of Covid-19 [14]. Higher ACE2 expression in the lungs, as found in diabetics, has also been linked to increased susceptibility to SARS-CoV-2 infection and diabetes [15]. Certain drugs used for the treatment of diabetes may increase the level of ACE2 further
[16]. The states with high burden of diabetes recorded high caseload of Covid-19. Previous studies from India also found diabetes as a risk factor for infection $[17,18]$.

The present study found a significant association between Covid-19 and hypertension. It is in accordance with the previous findings $[17,18]$. Elevated troponin $\mathrm{T}$ seems to be a common factor for patients succumbing to Covid-19 [19]. A meta-analysis suggested that underlying cardiovascular diseases including hypertension could render anyone susceptible to Covid infection [3]. The relationship between cardiovascular pathologies and Covid-19 may be the factor that determined the caseload in individual states. Goa, Kerala and Delhi are examples of such relationship. Clinically severe patients were more prone to have complications and comorbidities including hypertension and other cardiovascular diseases [20]. Covid-19 seems to play a crucial role in the development of cardiovascular disorders including myocardial injury, arrhythmias, acute coronary syndrome (ACS) and venous thromboembolism [19,21]. Another study from Germany indicated that cardiac involvement was found in $78 \%$ patients while ongoing myocardial inflammation in $60 \%$ patients [22].

Some studies found obesity as the most common co-morbidity in Covid-19 patients [23-25]. The present study also found an association of Covid burden with overweight and obesity. It was one of the risk factors responsible for sub-national heterogeneity, as evident by its prevalence in high-burden states. It may be mentioned that obesity could change immune responses and is associated with dyslipidemia [26]. It could be one possible mechanism in Covid19 for posing a higher risk.

A meta-analysis indicated asthma as the most common lung morbidity with Covid-19, followed by COPD and lung cancer

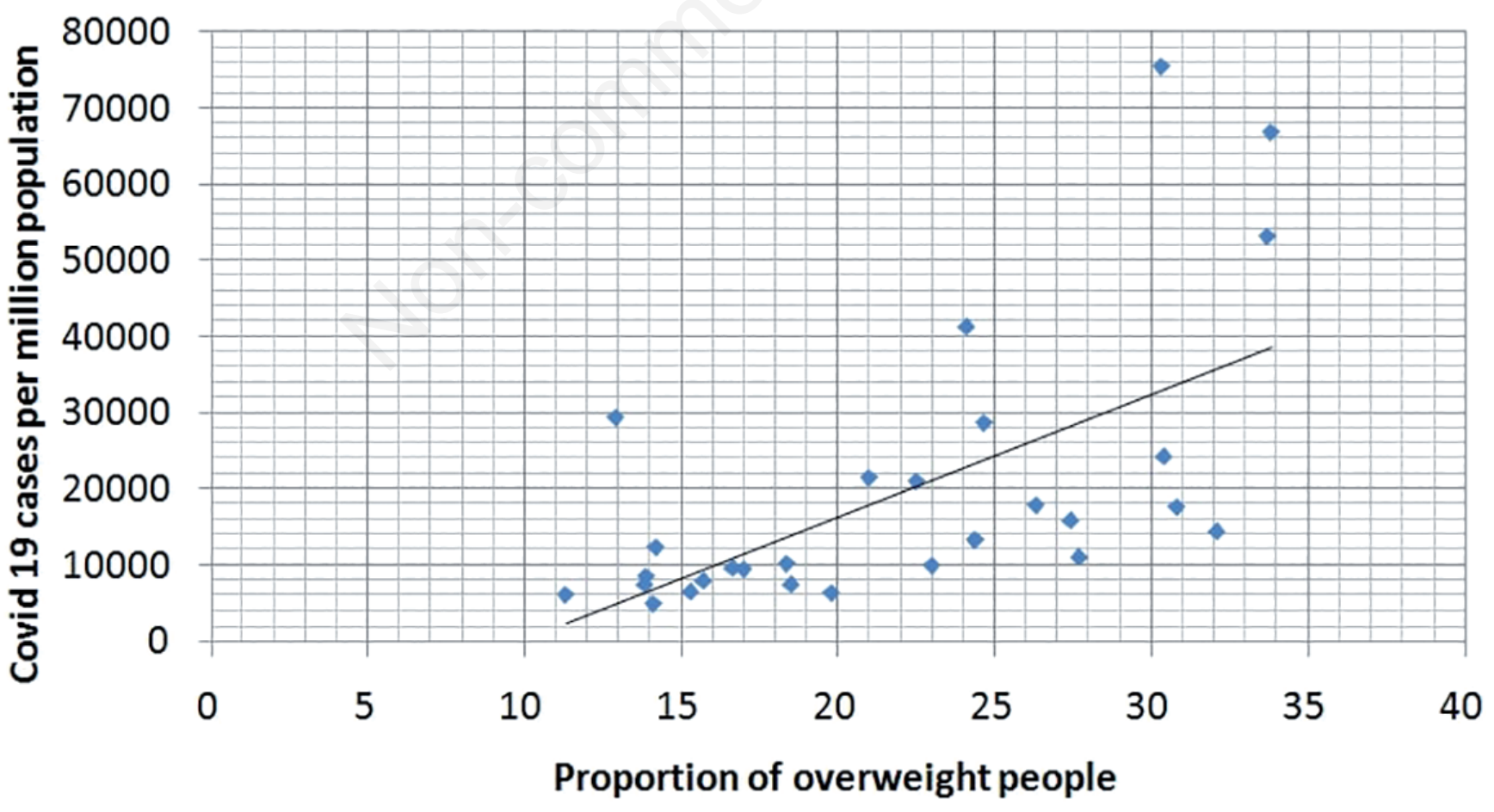

case per million — Linear (case per million)

Figure 2. Relationship between overweight and Covid 19 cases per million in India. 
[27]. The present study could not find any correlation between the prevalence of CLD and the burden of Covid-19.

\section{Limitations}

Being ecological and self-reported data on co-morbidities are two limitations of this study. As there is no national registry with individual data on co-morbidity in India, LASI report plays the role of a surrogate databank. Use of individual records would have improved the scope of extrapolation of the analyzed report of the present study. The prevalence of co-morbidities was considered for people $>45$ years. No data were available on delay in getting test reports for Covid, a factor that could have influenced the further spread of the infection, particularly from asymptomatic cases. Use of multiple regression would have addressed the issue pertaining to confounders, as Covid burden could be best described by an outcome of complex interplay several known and unknown factors. However, putting data from different sources for building a national perspective for Covid is not very common in India. From that point of view, this study stands unique.

To sum up, the burden of Covid-19 was associated with the presence of co-morbidities and demographic factors. The states with poor literacy and health condition bore the brunt of the pandemic. Tailored intervention is wanted to reach the vulnerable and alleviate their sufferings. The findings may help tailor public health strategies for mitigation of the burden of Covid-19.

\section{References}

1. COVID19INDIA. Last accessed 9th May, 2021. Available from: https://www.covid19india.org/

2. Hawkins RB, Charles EJ, Mehaffey JH. Socio-economic status and COVID-19-related cases and fatalities. Public Health 2020;189:129-34.

3. Badawi A, Ryoo SG. Prevalence of comorbidities in the Middle East respiratory syndrome coronavirus (MERS-CoV): a systematic review and meta-analysis. Int J Infect Dis 2016;49:129-33.

4. Emami A, Javanmardi F, Pirbonyeh N, Akbari A. Prevalence of underlying diseases in hospitalized patients with COVID-19: a systematic review and meta-analysis. Arch Acad Emerg Med 2020;8:e35.

5. International Institute for Population Sciences (IIPS) and NPHCE, MoHFW. Longitudinal Ageing Study in India (LASI) Wave 1, 2017-18, Factsheets - States/UTs, International Institute for Population Sciences, Mumbai; 2020.

6. Government of India, Ministry of Finance, Department of Economic Affairs. Economic Survey 2020-21 Volume 2. Last accessed on 17th February, 2021. Available from: https://www. indiabudget.gov.in/economicsurvey/doc/echapter_vol2.pdf

7. Government of India, Ministry of Statistics and Program Implementation. Household social consumption on education in India. NSS 75th round. New Delhi; 2020.

8. Christy JS, Kaur K, Gurnani B, et al. Knowledge, attitude and practise toward COVID-19 among patients presenting to five tertiary eye care hospitals in South India - A multicentre questionnaire-based survey. Indian J Ophthalmol 2020;68:2385-90.

9. Cifuentes MP, Rodriguez-Villamizar LA, Rojas-Botero ML, et al. Socioeconomic inequalities associated with mortality for COVID-19 in Colombia: a cohort nationwide study. J
Epidemiol Community Health 2021;jech-2020-216275. Online ahead of print.

10. Mena GE, Martinez PP, Mahmud AS, et al. Socioeconomic status determines COVID-19 incidence and related mortality in Santiago, Chile. Science 2021;372:eabg5298.

11. Guan WJ, Ni ZY, Hu Y, et al. Clinical characteristics of coronavirus disease 2019 in China. N Engl J Med 2020;382:1708-20.

12. Wu C, Chen X, Cai Y, et al. Risk factors associated with acute respiratory distress syndrome and death in patients with coronavirus disease 2019 pneumonia in Wuhan. China JAMA Intern Med 2020;180:934.

13. Guo W, Li M, Dong Y, et al. Diabetes is a risk factor for the progression and prognosis of COVID-19. Diabetes Metab Res Rev 2020; 3319 . Online ahead of print.

14. Mehta P, McAuley DF, Brown M, et al. COVID-19: consider cytokine storm syndromes and immunosuppression. Lancet 2020;395:1033-4.

15. Rao S, Lau A, So HC. Exploring diseases/traits and blood proteins causally related to expression of ACE2, the putative receptor of SARS-CoV-2: a Mendelian randomization analysis highlights tentative relevance of diabetes-related traits. Diabetes Care 2020;43:1416-26.

16. Erener S. Diabetes, infection risk and COVID-19. Mol Metab 2020;39:101044.

17. Yadav R, Acharjee A, Salkar A, et al. Mumbai mayhem of COVID-19 pandemic reveals important factors that influence susceptibility to infection. EClinicalMedicine 2021;35:100841.

18. Marimuthu Y, Kunnavil R, Anil NS, et al. Clinical profile and risk factors for mortality among COVID-19 in patients at a tertiary care centre in Bengaluru, India. Monaldi Arch Chest Dis 2021;1724. Online ahead of print.

19. Guo T, Fan Y, Chen M, et al. Cardiovascular implications of fatal outcomes of patients with Coronavirus Disease 2019 (COVID-19). JAMA Cardiol 2020;5:811-8.

20. Zhang T, Huang WS, Guan W, et al. Risk factors and predictors associated with the severity of COVID-19 in China: a systematic review, meta-analysis, and meta-regression. J Thorac Dis 2020;12:7429-41.

21. Shi S, Qin M, Cai Y, et al. Characteristics and clinical significance of myocardial injury in patients with severe coronavirus disease 2019. Eur Heart J 2020;41:2070-9.

22. Puntmann VO, Carerj ML, Wieters I, et al. Outcomes of cardiovascular magnetic resonance imaging in patients recently recovered from Coronavirus Disease 2019 (COVID-19). JAMA Cardiol 2020;5:1265-73.

23. Richardson S, Hirsch JS, Narasimhan M, et al. Presenting characteristics, comorbidities, and outcomes among 5700 patients hospitalized with COVID-19 in the New York city area. JAMA 2020;323:2052-9.

24. Hernández-Garduño, E. Obesity is the comorbidity more strongly associated for Covid-19 in Mexico. A case-control study. Obes Res Clin Pract 2020;14:375-9.

25. de Lusignan S, Dorward J, Correa A, et al. Risk factors for SARS-CoV-2 among patients in the Oxford Royal College of General Practitioners Research and Surveillance Centre primary care network: a cross-sectional study. Lancet Infect Dis 2020;20:1034-42.

26. Dhurandhar NV, Bailey D, Thomas D. Interaction of obesity and infections. Obes Rev 2015;16:1017-29.

27. Alkhathami MG, Advani SM, Abalkhail AA, et al. Prevalence and mortality of lung comorbidities among patients with COVID-19: A systematic review and meta-analysis. Lung India 2021;38:S31-40. 